\title{
ROCKA, GAZTEON (ETA HAIN GAZTE EZ DIRENEN) PROTESTARAKO TRESNA
}

\author{
Asier García Lupiola \\ Universidad del País Vasco / Euskal Herriko Unibertsitatea. Dpto. Economía y Gestión
}

\section{Laburpena}

Musika-genero baino gehiago bilakatu zen fenomeno sozialak zazpi hamarkada beteko ditu laster. Bere sorreratik rocka munduan zehar zabaldu zen protesta-mugimendu gisa. Bakarlari eta talde anitzek rocka osatzen duten estilo eta genero ezberdinak sortu dituzte, eta une bakoitzean gazteriaren askatasun grinak pertsonifikatu dituzte. Era horretan, azken hirurogeitahamar urteetan planetan zehar jazo diren ekonomia-, gizarte- edota politika- izaera duten gertaera nabarmenen aurrean, rocka salaketarako eta gizartearen nahigabea adierazteko bozgorailu bihurtu da, bereziki gazteen artean.

Hitz gakoak: HERRI MUSIKA; ROCK; GAZTERIA; PROTESTA; GLOBALIZAZIOA

\section{ROCK AS A TOOL FOR PROTEST OF THE YOUNG PEOPLE (AND NOT SO YOUNG PEOPLE)}

\section{Abstract}

The social phenomenon that became more than just a musical genre will soon turn seven decades. The transformation of rock into protest-movement which extended over the planet was possible thanks to artists and groups that have been creating the different styles that are included in rock and that personified at all times the yearnings for freedom of the youth. In this sense, rock has served as a loudspeaker for the denunciation and expression of social discontent against the great political and economic events that have taken place throughout the planet during the last seventy years, especially for the young people.

Keywords: POPULAR MUSIC; ROCK; YOUTH; PROTEST; GLOBALIZATION

García Lupiola, Asier. 2021. "Rocka, gazteon (eta hain gazte ez direnen) protestarako tresna ". AusArt 9 (1): 101-115. D0I: 10.1387/ausart. 22565

\section{AUSART}




\section{SARRERA}

Rockak oraingo munduko herri-musikaren estilo eta genero desberdinak hartzen ditu bere baitan, nahiz eta musikaz harago doan fenomeno sozial bat izan. Bigarren Mundu Gerraren (BMG) ondoren ezarritako nazioarteko ordena ekonomiko berrian agertu zen rocka; eta planeta osoan hedatu zen protesta-mugimendua bilakatu zen. Ekonomia-, gizarte- edota politika- izaera duten gertaera nabarmenen aurrean salaketarako eta gizartearen nahigabea adierazteko gizarteak berak erabili dituen tresnen artean nabarmentzeko bozgorailu bihurtu da, bereziki gazteontzat. Ikuspuntu horretatik, musikaren historian zehar gertatu bezala, non gizartearen oinarriak kolokan jartzen dituzten aurrerapenak probokatzaileek eta erreboltariek eginak bait diren (Gioia 2020), rocka aldaketarako katalizadorea izan da.

$X X$. mendearen erdialdetik, aldaketa sozial masiboekin batera pertsona ugari agertu ziren herri-musika egiten zutenak eta beste milioika gehiago musika hura entzun, dantzatu, eta bere bitartez euren bizitza bizitzen zutenak (Ward eta Delgado, 2018). Horrela, historia garaikidea ulertzeko oinarria da rocka, garai aldakorren soinu-banda, eta gazteek nahi luketen mundua deskribatzen du (Assante 2008). Rockak gaur eguneko herri-kulturan ageri diren kontraesaneko bi elementuak biltzen ditu (Rowe 1995): batetik, produktuen merkaturatzea eta marketina eta, bestetik, independentzia- eta erresistentzia- jarrera, azken hau gazteriarentzako oso erakargarria. Rockak gazteei manifestatzeko eta antolatzeko tresna berria eskaini zien eta garai eta leku bakoitzean gazteriarentzako ahalduntzeko aukera erraztu du (García López 2020).

\section{SORRERA ETA HEDAPENA}

Rocka 1950eko hamarkadaren lehenengo erdian sortu zen, Amerikako Estatu Batuetan (AEB). Berez, hirietako gazteontzat oso erakargarri izango zen musika landa-eremuan jatorria zuten elementu desberdinak elkartzetik sortu zen: musika zuria (country\&western eta folk) eta, bereziki, beltza (rhythm \& blues, boggie woogie eta swing). Rock and roll terminoa rhythm\&blues-eko abeslariek erabili izan zuten sexu-harremanak aipatzeko, musikari jarraitzen zion dantzaren erritmoarekin identifikatu ohi baitzuten. 1952tik aurrera termino hori erabiliko da irratietan programatzen ari ziren musika-fenomeno berriaren abestiak aipatzeko. 
Sarritan hitz egiten da rockaz musika-generotzat hartuta, ordea, hasieratik musika-estilo berri bat baino askoz ere gehiago zen, hain zuzen, zentzurik zabalenean hartu beharreko musika-kultura (Keightley 2006). Musikak gai sozio-politiko eta kulturalekin lotura izateaz gain, sentsibilitate estetikoekin eta belaunaldien afektuekin lotura du ere (Bennett \& Rogers 2016), eta rocka idei horren oso adibide argia bilakatu zen hasieratik. Garaiko gazte estatubatuarrak gerra osteko belaunaldi bat ziren, american way of life horretaz gozatzen zuten baina, aldi berean, egoera ziurgabe batean bizi ziren; are gehiago, Gerra Hotzak eta arma nuklearrek adierazten zuten mehatxuaren pean. Gazteok beren prestigio-sinboloak nahi zituzten, hizkuntza propio bat, eta lehen aldiz historian, ez zuten beren gurasoak bezalakoak izan nahi (Assante, 2008). Desengainatuta sentitzen ziren eta ez zuten betiko abestiak entzun nahi, gizarte kontserbadore batentzat egindakoak; ordea, desadostasuna ezaugarritzat zuen soinu berri hori aukeratu zuten (Vázquez 2019).

Hasierako rock and roll artista arrakastatsuenen artean aipa daitezke Bill Haley, Jerry Lee Lewis, Roy Orbison, Buddy Holly, Carl Perkins, Gene Vincent, Little Richard, Chuck Berry, Bo Diddley edo Fats Domino. Dena den, bere nortasunari, bere ahotsari eta bere karismari esker, Elvis Presley bilakatu zen orduko herri-musikarekiko eta tradizio moralen hausturaren irudi. Hark bezala beren bizitza eta mundua aldarazi nahi zituzten gazteen begikotasuna bereganatu zuen Elvisek, erakutsitako jarrera harroputzagatik eta haren jatorri xumeagatik. Gazteak tradizioaren etengabeko jazarpenetik askatzera eraman zituen, eta horren oihartzuna planetako bazter guztietan entzun ahal izan zen (Sánchez 2012). Gainera, rockak zurien eta beltzen arteko oztopoak hautsi zituen, musika beltza ghettotik ateratzea lortu zuen eta arraza guztietako gazteek gogokoen zuten musikan bihurtu zen (Méndez 2004). Rockak ez zuen arrazari lotutako patroi jakin batzuen araberako entzule-eredu bat, eta horrela lortu zuen kultura-erreferente unibertsala izatea (De la Fuente 2007).

Rocka AEBetatik Europara iritsi zen eta Erresuma Batua izan zen sarbideko atea (Lonnie Donegan, Tommy Steele, Cliff Richard). Bi metropoli rockero horietatik abiatuta, agerikoa da rocka hedatu eta nagusitu egin dela kultura ez anglofonoetan pop-rockizazioaren bitartez (Regev 2002). Alderdi hau dela eta, joera nagusiari jarraitzen diogu, baina ez litzateke ahaztu behar herri-musikaren aurreko mende erdia, eta ez litzateke artista anglosaxoietan oinarritu behar ere, bereziki AEBetako eta Erresuma Batuko haietan (Egan 2009). Horrela, Europako beste herrialde batzuetan ere bizkor barneratu zen rocka, zegozkien musika-estilo eta gizarte-arauetara egokituta, tokiko musika-industriek saialdiak egin baitzituzten beren bertsioak sortzeko, 
Frantzian, Italian, Grezian eta Alemanian, adibidez (Kouvarou 2015). Mundu osoko gazteen artean zabaltzen hasitako erlijio berri baten moduan sortutako fenomeno baten isla zen hura, eta agintea eta ezarritako ordena desegitea baino ez zuen dogmatzat.

Gazteak masiboki bertaratu ohi ziren beren idoloen kontzertuetara baita dendetara ere haien diskoak erostera. Hala hasi ziren gazteak existitzen ikuspuntu ekonomiko batetik begiratuta (Serbia, 2018), eta negozio aukera bikaina zabaldu zen industria diskografikoarentzat. Iparamerikako industria horrek bere produktu nagusi bihurtu zuen rocka, eta screen stars izarren fenomenoa sortu zuen. Elvis Presleyren kopiak ziren, rockaren erritmoaz baliatzen ziren abestiekin. Ordea, abesti horien letrek albo batera uzten zituzten AEBetako barne-arazoak, besteak beste, arrazakeria edo Macarthismoaren sorginen ehiza, baita nazioarteko arazoak ere, Gerra Hotzak eragindakoak (Kubako misilen krisia edo Vietnameko gerraren hasiera). Musikaren historian askotan gertatu bezala, agintariek errebeldeen abestiak mehatxu gisa hartu zituzten eta horiek purifikatu eta berrinterpretatu zituzten (Gioia 2020). Horrela, 1960ko hamarkadaren hasieran rockaren espiritu subertsiboak galdu egin zuen indarra, screen stars izarren eragina jaso zuen bigarren belaunaldi bat agertu zenean.

Ordea, Europako gizartea bazegoen prest rockak ekartzen zuen kultura-iraultzarekin jarraitzeko (Stornaiolo 2019). Hala, Ingalaterran berreskuratu zuen rockak bere hasierako filosofia, bai jarrerari bai soinuari dagokienez. Beatles eta Rolling Stones taldeak ez ezik, beste talde batzuk ere sortu ziren (The Who, The Animals, The Kinks, The Hollies, The Zombies, The Small Faces). Banda britainiarrek berriro heldu zioten rockari gazteen bizipenak eta arazoak adierazteko baliabidetzat hartuta. Beatles taldea rock klasikotik pop-era pausua emanez masen fenomeno bihurtu zen planeta osoan, eta horrela iritsi zen poparen merkatua nerabeen ia esparru esklusibo bat izatera (Frith 2006). Rhythm\&blues musikatik gertuago, Rolling Stones taldeak mutil maltzurren irudia zuen, gazteen artean oso erakargarria.

1965rarte rockaren izaera inkonformistari folk abeslariek eutsi zioten AEBetan (Peet Seeger, Woody Guthrie, Joan Baez, Bob Dylan). Hortik aurrera rocka suspertu zuten bandak agertu ziren. Hippi mugimenduaren eragina zuten eta psikodeliaz betetako rock garratza lantzen zuten (Jimmy Hendrix, Janis Joplin, The Doors, The Jefferson Airplane, The Grateful Dead, The Byrds, Frank Zappa). Sex, druggs and rock'n'roll-aren goren unea zen hura: alde batetik, bueltan zegoen rockaren izaera oldarkorra eta subertsiboa, bestetik, 
psikodeliak bizitza optimismoz ospatzeko joera erakutsi zuen. Horrela, 1964 eta 1968 urte bitartean aldaketa estilistiko bizkorrak gertatu ziren. AEBetatik eta Erresuma Batutik sortutako soinuek elkarri lotu eta sendotu egin zuten rocka, 'n'roll atzizkia galduta (Keitghtley 2006). Rockak mundutik zehar zabaltzen jarraitu zuen, mota guztietako musika- eta kultura- adierazpenekin nahastuz (Stornaiolo 2019).

Orokorrean, peace and love mugimenduaren goren unea izan zen hamarkada hura. BMGaren ondoren jaiotako lehenengo belaunaldiak hogei urte betetzen zituen eta bere buruari galdetzen zion nola izan zen posible izugarrikeria hura. Pentsamendu kritikoa orokortu zen, zeinaren bitartez gazteak, berriz ere, ondorio berera iritsi ziren: ez zuten haien gurasoek izan zutena bezalako etorkizun bat nahi. Guzti horri esker, 1960koa hamarkada mitiko bat izatera iritsi zen: asalduraren garaia, protesten eta ametsen hamarkada (Méndez 2004). Testuinguru horretan jaialdi handiak antolatu ziren, gerren kontrako mezu argi eta zuzena zutenak: 1967an Monterreyko jaialdia Kalifornian, 1968an Erresuma Batuko Wight uhartean eta 1969an New Yorkeko Woodstock famatua.

Rock-protesta, hippismoaz eta psikodeliaz blaitua, bere goren unera iritsi zen eta garai hartako gertakari nabarmenenen isla izan zen (batzuk goraipatuak eta beste batzuk protesten bidez gaitzetsiak): Pragako Udaberria, Frantziako maiatza, Martin Luther Kingen eta Bob Kennedyren hilketak, Vietnameko gerra, deskolonizazio prozesua eta abar. Rockaren arrakasta mundu osoan zabaldu zen, mendebaldeko herrialdeetan batez ere. Diktaduraren menpe zeuden herrialdeetan (Espainian, Grezian edo Portugalen) zentzura zorrotz bati aurre egin behar izan zion. Herrialde komunistetan, rocka mugimendu kontrakultural gisa indartu zen, baina aginteak oztopoak jartzen zizkion, arrisku kapitalistatzat hartzen baitzuen. Afrikan, independentziaren aldeko gerrek edo Gerra Hotzaren ondoriozkoek ez zuten ia aukerarik ematen musikaren aisiaz gozatzeko. Latinoamerikan, demokrazien korrupzioak, diktadurek eta barruko gerrek eragotzi egin zuten rocka aise zabaltzea.

1970. hamarkadaren hasiera sormen handikoa izan zen rockaren munduan. Berdinik izango ez zuen garai bat zen; ideiak, sentsazioak, soinuak, dena zen posible eta halaxe izan zen (Sierra i Fabra 2003). Estiloei begiratuta, garai ona izan zen hura rock progresiboarentzat (Jethro Tull, Pink Floyd, Genesis, King Crimson, Supertramp, Yes). Aldi berean, zenbait bandek (Led Zeppelin, Deep Purple, Judas Priest, Black Sabbath) gogortu egin zuten soinua, eta hala sortu zen hard-rocka. Bakarlari batzuek pop-rock intimista bati ekin zioten (Carole King, Joni Mitchel, James 
Taylor). Jamaikatik reggae musika iritsi zen (Bob Marley, Jimmy Cliff, Peter Tosh). Eta glam-rock generoak ere fama ezagutu zuen (David Bowie, The New York Dolls, Roxy Music). Estiloak nahastuz, Europako artista askok mundu mailako arrakasta lortu zuten, britainiarrak (Queen, Mike Olfield) eta britainiarrak ez zirenak (Shocking Blue, Focus, Tangerine Dream, Can, Blue Suede, Abba).

\section{KRISIA ETA SUSPERRALDIA}

1973an, rocka bere une gorenean zenean, eztanda egin zuen krisi ekonomikoak, rocka modu desberdinetan erasan zuenak. Gazteek eta herritar orok diru gutxiago zuten aisiarako eta, beraz, disko gutxiago erosten ziren eta kontzertuetara joaten zen publikoa ere urriagoa zen. Konpainia diskografikoek artista handiengan soilik jarri zuten konfiantza, banda berrien alde apustu egin gabe. Ondorioz, gazteek utzi egin zioten beren burua identifikatzeari rockeroaren irudiarekin, jende eta gazte arrunten eguneroko bizitza latzetik urrundutako rock izarra. Gazteek etsita ikusi behar izaten zituzten astero telebistan prezioen etengabeko igoerari eta fabriken itxierari buruzko berriak; eta ez zuten rock zahar, kexati eta baldar hura entzuteko aukerarik ere, itxaropen falta saihestu ahal izateko (Méndez 2004).

Erresuma Batuan genero berri bat sortu zen: punka. 1976ko amaieran, gazteria britainiarrak, kontentagaitz eta erreferentziarik gabe, haientzat etorkizunik ez zegoela ondorioztatu zuen. No future izan zen araurik ez zuen mugimendu inkonformista haren lema, eta jatorrizko rockaren soiltasunera (gitarra, baxua, bateria) bueltatu zen baina oso soinu latzarekin eta oso letra zuzen eta iraingarriekin. Zarata izugarria sortzeaz gain, punkak kontzientziak piztu zituen (Assante, 2008), eta DIY (do it yourself) mugimenduari garrantzi kritikoa eman zion. DIY kontzeptuak aditu batengana jo gabe gauzak sortu, konpondu edo moldatzeko aukera adierazten du eta punkaren musika- eta kultura- izaerak indartsu barneratu zuen idei hori (Bennett, 2018). Sex Pistols izan zen banda karismatikoena, nahiz eta izan ziren beste batzuk ere (The Damn, Generation X, The Misfits) eta beste batzuek jarrera bera hartu zuten (The Ramones, Iggy Pop). 
Punka, berez, hamarkada bukatu baino lehen itzali zen konpainia diskografiko handiek hartutako jarreragatik. Gazteek punka eskatzen zutenez, banda ugari fitxatu eta sortu zituzten, punkak berezkoa zuen mezua bigunduta (AEBetan screen stars izarrekin gertatu bezala), eta horrela desagertu zen punkaren existitzeko arrazoia. Biziraun zuten bandek beste joera batzuetarantz eboluzionatu zuten (The Clash, The Jam, The Specials, Madness) eta punka gaindituta, Erresuma Batuan kalitatea helburu nagusitzat zuten taldeak sortu ziren (The Pretenders, The Police, Dire Straits).

AEBetan jatorrizko rockean oinarrituta, konpromiso sozial nabarmena zuten artistak, langile-klasearen ikono bihurtu ziren (Bruce Springsteen, Tom Petty, John Cougar/Mellencamp). Ipar Amerikan bertan, krisi latzaren eta bere ondorioen aurrean beste ihesbide bat aurkitu zuten gazteek eta ez hain gazteek (Allende 2007): hiri handietako diskoteketara joaten ziren, dibertitzeko, eguneroko nahigabeez, langabeziaz eta etorkizun ziurgabeaz ahazteko, eta horrek ekarri zuen berekin disco sound delakoa (Donna Summer, Earth-Wind \& Fire, Bonney M, Kool \& the Gang, Village People). Dance kultura ere deiturikoa, gizartearen ihesbide bat baino zerbait gehiago dela esan daiteke, era askotan egiten bait die aurka ideia eta esperientzia hegemonikoei oso maila sakonetan (Gilbert \& Pearson 2003).

Gizarteak krisiaz eta berau gainditzeko ezarritako neurriez ahazteko zuen gogo biziagatik, baita krisia gainditzen hasitakoan zabaltzen ziren aukerengatik ere, 1980ko hamarkadan era askotako musika-estiloak eta generoak agertu ziren, batzuk rockaren fenomenotik zeharo urrunduta. Gainera, industria diskografikoa telebistaz baliatzen hasi zen (MTV Music Television izan zen katerik ikusgarriena) eta, beraz, irudiari garrantzi handiagoa ematea ekarri zuen horrek berekin. Gauzak horrela, oso bideo zainduei esker lortu zuten hainbat artista kaskarrek ospea lortzea, talentu handiagoko abeslariek beren musika sustatzeko eginahalak egin behar izan zituzten bitartean (Bergamini, 2006). Are gehiago, bideo musikala banalizazio terminoetan erabili zen eta gazteak kontrolatzeko tresna politiko bilakatu zen (De la Fuente 2007).

Hard rockaren garapen gisa askorentzat rockaren salbabidea izan zena iritsi zen: heavya, harrezkero erreferentzia izango dena, neurri batean, rockaren soinuari dagokionez. Bi korronte nabarmendu ziren hasieratik. Batetik, rock-heavya, 1970eko hamarkadan jada arrakastatsu ziren hard-rock taldeek garatua (ACDC, Scorpions, Kiss, Aerosmith), eta haiei elkartu zitzaizkien talde 
berriak (Whitesnake, Deff Leppard, The Cult, Bon Jovi, Guns'n'Roses). Rock gogorrak xurgatu egin zuen neurri batean punkaren izaera konformagaitza eta horrekin gazteek burla egiten zieten portaera burgesei, sarri asko portaera bortitzak ere berekin ekarriz (Bergamini 2006). Bestetik, heavy-metala (Van Halen, Iron Maiden, Motorhead, Manowar), rock purua deiturikoa, Bluesaren oinordekoa, gazteok beren asaldatzea bideratzeko aterpea (Castaño 2010).

Garai honetan, punkaren eragina berandutxo heldu zeneko lurralde batzuetan protestak indar handia mantendu zuen neoliberalismoaren aurka. Horren adibide argienetarikoa Euskal Herrian dugu, non 1970eko hamarkadaren bukaerako egoera politiko-ekonomikoak euskal herri-musikan aldaketa handia sortu bait zuen. Rock progresiboarekin hasi ziren taldeen ostean (Errobi, Itoiz), hard-rockak eta bereziki punkak itzelezko bultzakada eman zion talde berrien sorrerari. 1980ko hamarkadaren hasieran industria-birmoldaketaren eragin latzak jasaten ari zen gazteriak sortu zituen talde asko "euskal rock erradikala" izeneko mugimenduan batu ziren (La Polla Records, Barricada, Hertzainak, Zarama, Cicatriz, Eskorbuto, RIP, Kortatu, Delirium Tremens).

Popak bere muga estilistikoak zabaldu zituen, pop-rock gitarreroenetik soinu elektronikoraino, eta gazteen artean euren gustuak asetzeko aukera zabala eskaini zuen. Batzuek soinu teknologikoak (tecno-pop) indartu zituzten (Yazoo, Pet Shop Boys, Human League, Depeche Mode). Tonu komertzial baina dotorea lantzen zutenen artean new romantics deituriko taldeak zeuden (Spandau Ballet, Duran Duran, Wham) baita mega izarrak ere (Michael Jackson, Prince, Madonna). Bazeuden gitarren presentzia handiagorekin abestien letretan konpromiso soziala adierazten zutenak (U2, Simple Minds, Manic Street Preachers, Talking Heads). New Wave deitu zitzaion generoaren barruan, berriz, post-punketik zetozen taldeak zeuden (The Cars, The Go-Go's, Men at Work), askotan indie edo rock alternatiboan sailkatutakoekin nahasten zirenak (The Smiths, The Cure, B-52's). Konpromiso sozialatik politikora heltzen ziren bandak ere bazeuden (REM, Nick Cave, Midnight Oil). Rapa estilo berria sortu zen, rockaren soinutik urrunago, baina haren izaera inkonformista eutsita.

\section{GLOBALIZAZIOA}

1990eko hamarkadaren hasieratik rock musikan sortu ziren estiloen artean grunge musika nabarmentzekoa da. Seattlen sortua, $X$ 
belaunaldiaren musika izan zen: nahigabearen eta, Gerra Hotza bukatuta, gerraoste berriaren belaunaldia. Sorburuetako rockaren baliokide zen grungea (gitarra, bateria eta baxua); heavyaren indarra eta punkaren oldarkortasuna, jarrera axolagabea eta isolamendua elkartzen zituen. Giro goibelak eta itxaropenik gabeak islatzen zituzten grunge musikako abestiak, baita huts egitearen eta paranoiaren inguruko istorioak, oso arruntak garai hartako gazteen artean (Bergamini 2006). Hala, horrek pentsarazten digu mugimendua gazteen aldetik arreta erregutzen zuen adierazpide baten bilaketa izan zela (Méndez, 2004). Neoliberalismoak ekarri zituen arau kulturalei egiten zien desafioak, nahiz eta asaldatzeko asmorik ez erakutsi, eta 1980ko hamarkadan luxuari lotuta nagusitu zen rockari zion gaitzespenak bihurtu zuten grungea arrakastatsu. Deigarria zen 1990eko hamarkadaren hasierako gazteriaren kontraesana, zeren eta, gaitasuna erakutsi bazuen ere bere ingurune sozialaren kritika zorrotza adierazteko, ez baitzen gai izan kritika hori gauzatzeko (Abad 2002).

Erreferentziazko banda Nirvana izan zen eta askorentzat taldeak iraun zuena iraun zuen grungeak, punkarekin eta Sex Pistolsekin gertatu bezala, nahiz eta beste banda handi batzuk izan ziren ere (Pearl Jam, Alice in Chains, Soundgarden, Stone Temple Pilots). Punkarekin gertatu bezala, industriak fagozitatu egin zuen grungearen autentikotasuna, baita mugatu ere azaleko estetika sinple batera, sistema zalantzan jarriko ez zuten produktuak saltzea lortzeko (Gil 2004).

1990eko hamarkadaren bigarren erdian, jatorrizko rockatik gertuen zeuden estiloek (pop-rocketik heavyra) berreskuratu egin zuten rockatik gehien aldendu ziren beste estilo batzuek irabazitako eremua (pop melodikoa, rap, pop elektronikoa, talde komertzial huts-hutsak jarraitzaile gazteenei zuzenduak). Erresuma Batutik britpopa edo power-popa gailendu zen, banda ugari eta arrakastatsuekin (Oasis, Blur, Supergrass, Pulp, The Verve, Suede, Radiohead). Rock alternatiboan, artista ugari agertu ziren (Alanis Morrissette, Hootie \& the Blowfish, Counting Crows, Matchbox Twenty, The Wallflowers, Silverchair, P.J. Harvey) baita soinu gogorragoa zutenak ere (Red Hot Chilli Peppers, Green Day, Offspring, Marilyn Manson). Trash Metal estilo berria sortu zen (Metallica, Slayer, Anthrax, Megadeth) eta heavy-metala musika estilo desberdinekin nahastetik, nu-metal (Korn, Limp Bizkit, Linkin Park, Deftones, Evanescence).

Konpainia diskografikoei irabazi gehien eman ziena nerabeentzako pop komertziala izan zen (Spice Girls, Britney Spears, Back Street Boys, 
Christina Aguilera, N'Sync). Konpainiek sortutako Boy eta girls band haiek marka bat bezala funtzionatzen zuten, sexuaren ezinbesteko erakargarriarekin saltzen ziren kontsumo-lerro desberdinekin batera, bereziki, jantziak eta osagarriak (Gil 2004). Jarrerari dagokienez, rock mundutik aldentzen diren artistak dira oro har, azaleko gaiak adierazten dituztenak konposizioetan, inolako salaketa edo protestarik egin gabe munduan gertatzen diren bidegabekerien aurrean. Eta, hain zuzen ere, beharbada hori izan zen neurri batean haien arrakastaren izateko arrazoia, musika horrek eguneroko bizitzatik deskonektatzeko balio zuelako, alegia. Nahiz eta gazteak entretenituta edukitzeko ere balio zuen, gai garrantzitsuagoek eragindako kezketatik urruntzeko.

XXI. mendea krisi berri batekin hasi zen musikaren industrian, pirateria deitutakoak eragindako krisi ekonomikoa. Rockaren angloestatubatuar inperialismoarekiko haustura gisa ikusi da ere pirateria, batetik musikaren industria globala AEBetakoa soilik ez delako, eta bestetik pirateriak batik bat tokiko grabazioak erasaten dituelako bereziki (Frith 1999). Paradoxikoki, konpainia diskografikoek arindu egin zituzten pirateriaren ondorioak, agintariek aisia indartu izanari esker. Izan ere, nazioarteko terrorismo fundamentalistaren ekintzek (2001eko New Yorkeko erasoekin hasita) gizartean izan zituen ondorioek zabaldu egin zuten izua eta horregatik indartu ziren distrakziorako produktuak, zinemaren, telebistaren eta musikaren bidez eskainiak. Bitxia dirudien arren, gerra garaietan, aisia eta entertainmenta handitu egiten dira inguratzen gaituzten arriskuek eragindako beldur eta ezegonkortasun sentsazioa arintzearren (Sierra i Fabra 2003).

Musikaren eremuan, herritarren eta, bereziki, gazteen entretenimendua indartzeko asmoz konpainia diskografikoek genero eta estilo berriak sortuko dituzte, merkatu bakoitzari zer genero mota dagokion erabakita eta, berriro ere, musika merkantzia bilakatuta (Frith 1996). Adibide argia da haurrek eta nerabezaroaren aurrekoek osatutako publikoarentzat sortutako merkatu musikala telebistetan, zineman eta aldizkarietan (Goialde 2013), izar ugari dituena (Hannah Montana, Jonas Brothers, Selena Gomez, One Direction). Beste adibide bat indie-rock delakoan dugu: jatorrizko rockaren antisistema izaera zuena, gaur egun marketin estrategia gisa erabiltzen da, salmenta handiak lortzeko etiketa (Criado 2014).

Dena den, irudi interesgarriak ere sortu izan dira estilo desberdinetan: pop-rockean, nabarmendu egiten dira soinu dotorea duten bandak 
(Maroon 5, Coldplay, Keane, Snow Patrol); hard-rock klasikoa defendatzen dutenak (The Darkness, Airbourne, Audioslave, The Answer); 1970eko hamarkadako elementu musikalak eta estetikoak berreskuratuz, rock alternatiboa eta post-punka elkartzen dutenak (The Strokes, The White Stripes, Kings of Leon, Jet); baita ukitu elektronikoak gehitzen dituztenak ere (The Killers, Franz Ferdinand, The Bravery); eta rapa berriztatu eta hip hopa lantzen dutenak (Eminem, Jay Z, Nelly, Black Eyes Peas). Bestalde, ugariak dira 2000az geroztik indarberrituta ageri diren estiloak eta generoak, denboraren joana gainditu eta desagertuko ez direnak. Hala, doom metal, death metal, ska, punk klasikoa, LA hardcore, garaje psikodelia, funk, indie pop, rockabilly, swing, laurogeiko urteetako electrobeata, musika elektroniko alemana eta beste hainbat estilo, oraindik ere hor jarraitzen dutenak beren biziraupena bermatzen duten jarraitzaileen sareetan (Straw 2006, 107). Horietako batzuetan, hala nola, anarcho-punk, gothic-punk eta hardcore, posible da punkek ezarritako DIY mugimenduaren oinarriak aurkitzea (Bennett 2018).

2008an krisi ekonomiko berriak eztanda egin zuen eta, berriro ere, herrialde gehienetan aisia bultzatu zen gizartearen kezkak arintzeko. Musikaren arloan, horren ondorio dugu krisian zehar pop komertzialena indartu izana eduki gatzgabeekin eta, paradoxikoki, indar handiagoaz krisiaren irtenaldian. Hortaz, aurrean dugun egoera da ospeak eta aberastasunak, berehalako aisiak eta guztiak balio du ideia postmodernoak liluratutako gizarte baten adierazpena (Gil 2004). Protesta-rocka idazten jarraitu arren, industria diskografikoak baztertu egiten du, hipnotizatuta baitago get-famous-fast TV showsez, oso arrakastatsuak gazteon artean. Alde horretatik, aipatzekoa da kontrol bide gisa erabili nahi duten tresna horrek kontrako emaitzak ekarri ditzakela, egun telebistek eta sare sozialek bultzatzen dituzten estiloek, hala nola trap edo reggaeton, gazteon artean antisozial- eta delitu- jarrerak zabaldu bait ditzakete (Nanclares 2020).

Bestalde, egia da ere musika kontsumitzeko bidea aldatu egin dela. MP3 formatuaren bidez edo musika aplikazioen bidez, hala nola Spotify edo iTunes, abesti solteak entzuten dira eta diskoak alboratzen dira. Musika Interneten erraztasunez lortzea posible da ere, eta horretan industriak musika abesti-unitatetan eskaintzeak zerikusi handia du. Zoritxarrez, horrela, albumak dakarren osotasuna apurtzen da, artista edo taldea bera ezagutzeko aukera ematen duten elementuak desagertzen baitira. Formulazio horrekin musikak balioa galtzen du, erabili ondoren zaborretara botatzeko garrantzirik gabeko produktuan bihurtzen baita (Del Amo, Letamendia \& Diaux 2016). 
Hala ere, beste ikuspuntu interesgarria aipatu beharra dago ere. Azken berrogei urteetan zehar ospe handikoak izandako artista eta talde asko orokorrean guztiz ezezagunak dira gaur eguneko nerabe eta gazteentzat. Ordea, entretenimenduaren industriak, nerabe eta gazte horien artean oso arrakastatsuak diren musika bideo-jokoen bitartez, artista eta talde horiek -bereziki hard-rock eta heavy estiloetan- entzule eta jarraitzaile berri eta gazteak lortzea ahalbidetu du (Herschmann 2011).

\section{AZKENEKO GOGOETA}

Bada pentsatzen duenik aro berri bat hasi dela, copy-paste aroa alegia, non industria diskografikoaren estrategiak zenbaki estatistikoetan oinarritzen baitira: funtzionatzen duen soinua sustatzen da bakarrik (Sánchez 2012). Antza denez, industria horren helburua sail artistikoen gainetik marketinari are eta garrantzi handiagoa ematea izan da, beti salmentak handitzeko helburuarekin (Gil 2004). Hala eta guztiz ere, posible da baita ere protesta-mugimendu inkonformista bat topatzea, betidanik musikak arau sozialei eta agintariek defendatzen duten statu quo delakoari aurre egin bait dizkie (Gioia 2020). Eta hori argi ikusten da duela hamarkada batzuk kontsakratutako bandetan eta artistengan, baina baita duela gutxi sortutako beste batzuengan ere. Nolabait esateko, musikako izar guztien ezaugarri bat da, zeinak inoiz ez diren elikatu ikaratzeko moduko ideia kontserbadoreez, kontuan izanik, aitzitik, erakutsi egin dutela aurrera egiteko bokazioa, gauzak hobetzearen aldeko sentimendu anarkiko antzeko bat (Ruiz 2006).

Jarrera hori rock musikatzat hartzen den horretan biltzen diren estilo eta genero desberdinetatik sortzen da: rockaren soinu gogorrenean (hard-rock edo heavytik trash-metaleraino), aldenduenean (rap, hip-hop, reggae), baita komertzialenak diren soinuetan ere (pop, funky, disco). Hainbesteko dibertsitateak adierazten du gaur egun ez dela rock bakar bat existitzen, rock anitzak baizik, elkar topo egin eta elkar nahasten direnak, gurutzatzen diren gazte-hizkuntzak eta soinu zaharrak, desagertu baino indarberrituta itzultzen direnak (Assante 2008). Are gehiago, esan daiteke rockak planetako leku desberdinetan biltzen dituen elementu komunek ahalbidetu egiten dutela kulturen hurbiltzea (Regev 2013). Globalizazio garai honetan, rockak protesta-, justizia- eta berdintasun- idealak 
eskaintzen ditu oraindik ere, gazteok eta arima gaztea dutenek bereak egiten dituztenak (Vázquez 2019). Beraz, rocka gizartearen aurrean kokatzeko modua da oraindik ere, gizarte kontserbadore baten baloreei aurre egiten dion kontrakulturako mugimendua, eta gazteak aktibista bilakatzeko eragina du (Lozano 2019).

\section{Erreferentzia bibliografikoak}

Abad Morales, Luis Ángel. 2002. Rock contra cultura. Madrid: Biblioteca Nueva

Allende Portillo, Fermín. 2007. "El contexto económico de la música popular en el siglo XX". En Economía y rock: La influencia de las relaciones internacionales y la economía mundial en el rock, Asier García Lupiola, dir., 99-118. Leioa: Universidad del País Vasco

Assante, Ernesto. Leyendas del rock: Artistas, instrumentos, mitos e historia de 50 años de música. Barcelona: Blume

Bennet, Andy \& lan Rogers. 2016. Popular music scenes and cultural memory. London: Palgrave Macmillan

Bennett, Andy. 2018. "Youth, music, and DIY careers". Cultural Sociology 12(2): 133-9. https:// journals.sagepub.com/doi/full/10.1177/1749975518765858

Bergamini, Andrea. 2006. El rock y su historia. Ilustraciones de Manuela Cappon et al.; traducción de Virginia Pérez Moreno. Barcelona: Malsinet

Castaño Támara, Ricardo. 2010. "Ser joven y el mundo metalero". Educación y Ciudad 18: 12944. https://revistas.idep.edu.co/index.php/educacion-y-ciudad/article/view/172

Criado Calvo, Silvia. 2014. “Rock indie ¿Realidad o ficción?”. Síneris 16: 1-5. https://sineris.es/ arctic_monkeys.html

De la Fuente Soler, Manuel. 2007. "Tumbarse en los raíles: La presencia de la música rock en la política internacional". En Economía y rock: La influencia de las relaciones internacionales y la economía mundial en el rock, Asier García Lupiola, dir., 119-36. Leioa: Universidad del País Vasco

Del Amo, Ion, Arkaitz Letamendia \& Jason Diaux. 2016. " ¿El declive del significado social de la música?”. Revista Crítica de Ciencias Sociales 109: 11-32. http://journals.openedition.org/ rccs/6189

Egan, Sean, ed. 2009. 100 años de música: Momentos clave; Artistas, álbumes, canciones, conciertos y acontecimientos que han marcado el panorama musical. Traductores, Maite Rodríguez et al. Barcelona: Blume

Frith, Simon. (1996) 2014. Ritos de la interpretación: Sobre el valor de la música popular. Trad., Fermín Rodríguez. Buenos Aires: Paidós

Frith, Simon. 1999. "La constitución de la música rock como industria transnacional". En Las culturas del rock, Luis Puig y Jenaro Talens, eds. y trad., 11-30. Valencia: Pre-Textos

Frith, Simon. 2006. "La música pop". En La otra historia del Rock: Aspectos clave del desarrollo de la música popular; Desde las nuevas tecnologías a la política y la globalización, editado 
por Simon Frith, Will Straw \& John Street; traducción de Jorge Conde, 135-54. Barcelona: Robinbook

García López, Edgar Josué, ed. 2020. “Rock: Ingeniería en comunicación social, complejidad y cultura de participación; O de cómo abordar los estudios sobre las estéticas, las culturas y los siglos del rock". Estudios sobre las Culturas Contemporáneas 6: 241-62. https://www. culturascontemporaneas.com/articulos.htm?revista=88

Gil Rituerto, Pablo. 2004. El pop después del fin del pop: Entrevistas. Barcelona: RDL

Gilbert, Jeremy \& Ewan Pearson. 2003. Cultura y políticas de la música dance: Disco, hip-hop, house, techno, drum'n’bass y garaje. Traducción de Nuria Riambau. Barcelona: Paidós

Gioia, Ted. 2020. La música: Una historia subversiva. Traducción de Mariano Peyrou. Madrid: Turner

Goialde Palacios, Patricio. 2013. "Música popular/músicas urbanas”. Musiker 20: 7-18. https:// www.eusko-ikaskuntza.eus/es/publicaciones/musicas-urbanas-hiri-musikak/ar-23438/

Herschmann, Micael. 2011. "Repensando o sucesso dos videogames musicais na cultura contemporânea”. Redes.com 6: 301-16. https://redib.org/Record/oai_articulo576176repensando-o-sucesso-dos-videogames-musicais-na-cultura-contempor\%C3\%A2nea

Keightley, Keir. 2006. "Reconsiderar el rock". En La otra historia del Rock: Aspectos clave del desarrollo de la música popular; Desde las nuevas tecnologías a la política y la globalización, editado por Simon Frith, Will Straw \& John Street; traducción de Jorge Conde, 155-94. Barcelona: Robinbook

Kouvarou, Maria. 2015. "American rock with a European twist: The Institutionalization of rock'n'roll in France, West Germany, Greece and Italy (20th Century)". Historia Crítica 57: 75-94. https://doi.org/10.7440/histcrit57.2015.05

Lozano González, Elí Orlando. 2019. “Los ritmos de la rebeldía: La música en la formación de estudiantes activistas universitarios". Revista Mexicana de Ciencias Políticas y Sociales 237: 65-94. http://www.revistas.unam.mx/index.php/rmcpys/article/view/67674

Méndez Ramos, Sabino. 2004. Limusinas y estrellas: Medio siglo de rock 1954-2004. Madrid: Espasa

Nanclares González, Esther. 2020. “El rol de la música en la delincuencia juvenil: Un estudio exploratorio”. Boletín Criminológico 197: 1-30. https://revistas.uma.es/index.php/boletincriminologico/article/view/11282

Regev, Motti. 2002. “The 'pop-rockization' of popular music”. En Popular music studies, edited by David Hesmondhalgh \& Keith Negus, 251-64. London: Arnold

Regev, Motti. 2013. Pop-rock music: Aesthetic cosmopolitanism in late modernity. Cambridge: Polity

Rowe, David. 1995. Popular cultures: Rock music, sport and the politics of pleasure. London: Sage

Ruiz Garrido, Tomas Julián. 2006. Plásticos y decibelios: Toda la música de nuestro tiempo. Madrid: Aguilar

Sánchez, Mariano. 2012. "Música en vivo: Se hace camino al tocar". Live music experience, Catálogo de la exposición 'Cuatro décadas, 40 años de música en vivo', 15-32. Bilbao: AlhondigaBilbao 
Serbia, José María. 2018. "La domesticación de la cultura rock y la racionalización de la espontaneidad". Hologramática, 28(1): 19-109. http://www.cienciared.com.ar/ra/usr/3/206/ holo28_v1_p19_109.pdf

Sierra i Fabra, Jordi. 2003. La era rock (1953-2003). Madrid: Espasa

Stornaiolo Pimentel, Alfredo. 2019. "La contracultura beat: Un puente entre la música negra y el rock". Com Humanitas 3: 13-42. http://www.comhumanitas.org/index.php/comhumanitas/ article/view/212

Straw, Will. 2006. "El consumo". En La otra historia del Rock: Aspectos clave del desarrollo de la música popular; Desde las nuevas tecnologías a la política y la globalización, editado por Simon Frith, Will Straw \& John Street; traducción de Jorge Conde, 87-111. Barcelona: Robinbook

Vázquez Carmona, Alejandra. 2019. "La contracultura: El rock como protesta política”. El Artista 19: 1-14. https://www.redalyc.org/revista.oa?id=874\&numero=59435

Ward, Paul \& Ander Delgado Cendagortagalarza. 2018. "Introducción: Música popular, identidad y política”. Historia Contemporánea 57: 321-4. http://orcid.org/0000-0002-60449833 